\title{
Special issue: Covid-19 and the role of technology and pedagogy on school education during a pandemic
}

\section{Louise Starkey, Miri Shonfeld, Sarah Prestridge \& Mercè Gisbert Cervera}

To cite this article: Louise Starkey, Miri Shonfeld, Sarah Prestridge \& Mercè Gisbert Cervera (2021): Special issue: Covid-19 and the role of technology and pedagogy on school education during a pandemic, Technology, Pedagogy and Education, DOI: 10.1080/1475939X.2021.1866838

To link to this article: https://doi.org/10.1080/1475939X.2021.1866838

曲 Published online: 07 Jan 2021.

Submit your article to this journal $\asymp$

III Article views: 1152

Q View related articles $\asymp$

View Crossmark data 


\title{
Special issue: Covid-19 and the role of technology and pedagogy on school education during a pandemic
}

\author{
Louise Starkey ${ }^{a}{ }^{a}$, Miri Shonfeld ${ }^{b}$, Sarah Prestridge ${ }^{c}$ and Mercè Gisbert Cervera ${ }^{d}$ \\ aSchool of Education, Victoria University of Wellington, Wellington, New Zealand; ${ }^{\mathrm{b}}$ Faculty of Education, Kibbutzim \\ College of Education, Tel Aviv, Israel; 'School of Education and Professional Studies, Griffith University, Brisbane, \\ Australia; ${ }^{d}$ Department of Pedagogy, Rovira i Virgili University, Tarragona, Spain
}

When the Covid-19 pandemic swept across the world in 2020, schools closed and education was moved to students' homes. Consequently, many countries faced the challenge of an unanticipated and accelerated move to online learning. This represents a crucial time to consider technology, pedagogy and education. Digital technology played a significant role in enabling teachers to teach students at a distance using tools that enabled both synchronous and asynchronous communication with whole class, groups and individual children or young people; access to learning materials; and interactive and collaborative activities. This special issue examines how jurisdictions worldwide responded, the emerging opportunities and considerations; and what we can learn moving forward for the contemporary role of technology in education in times of crisis.

The call for the special issue resulted in 118 abstracts being received by the April 2020 deadline. The editors acknowledge all the researchers who submitted proposals. The 11 articles selected for this issue report studies undertaken rapidly in the first months of the pandemic from a range of contexts, using differing methodologies and which focus on various aspects including national policies and the experiences of parents, students, teachers and school leaders. The contexts include Afghanistan, Australia, Germany, Ireland, Italy, Kazakhstan, Libya, New Zealand, Palestine, Spain, Turkey, United States and the United Kingdom (UK). Examining the situation in different countries reveals themes of digital inequities, the influence of context, the need for emergency planning, and how technology mediates the role of parents, teachers and students in the process of learning, wellbeing and motivation.

Two specific contexts are examined in the first article by using document analysis methodology. US and UK media reports identified the tensions and contradictions within and between schooling, educational policy and home-learning during the Covid-19 period. The authors identified digital equity issues in both contexts with a greater coordinated response occurring in the UK national educational policy system than in the US, where parents received less support (Greenhow et al., 2020).

The second article in this special issue examines parental perception of the quality of learning their children received during Covid-19. In Kazakhstan, the state provided resources through print and television broadcasts to increase access to learning. Children experienced learning in different modes with combinations of text material, television broadcasts and online interactions (Bokayev et al., 2021). Older parents, those with higher family income and those with fewer children reported greater satisfaction. A tension that some parents reported was whether to follow public health recommendations or to allow their children to socialise to preserve their motivation and emotional wellbeing. The study identified a statistically significant association between parents' satisfaction

CONTACT Louise Starkey louise.starkey@vuw.ac.nz $\mathbf{E}$ School of Education, Victoria University of Wellington, Wellington, New Zealand

(c) 2021 Technology, Pedagogy and Education Association 
with the quality of education and their assessment of teacher competence and the level of government readiness to support learning at home during lockdown.

Australian students, parents and teachers were interviewed to examine their experience of learning when schools were closed. The third article compares emergency online learning against deliberate and well-designed online teaching (Ewing \& Cooper, 2021). The researchers found a lack of social interaction was a major challenge for many students, and teachers recognised this and prioritised engaging students by adjusting teaching practices for online interactions and engagement. However, the emergency technology adoption in schools did not enable the purposeful integration of technology, which likely limited the effectiveness of online learning. Technology was found to be enabling and constraining but not engaging. While students engaged with content, they did not achieve other aspects for effective online learning such as social, cognitive and teaching presence and supporting discourse. Motivation and engagement in learning was also a key theme identified through a survey of senior secondary students from New Zealand (Yates et al., 2020). The students in this study reported that authenticity and collaboration facilitated their learning, and they valued supportive pedagogies and motivational strategies which enabled their academic progress and enhanced wellbeing.

Student experience of learning at home was also the focus of an article from Turkey (Fiş Erümit, 2020). In this context, the government provided a range of websites and televised resources for students and online professional development for teachers. The televised resources were found to support students' learning and provided psychological support. The web portal gave students access to multimedia content, and synchronous lessons provided social interaction, motivation and opportunities to ask questions in real time. However, the students were concerned that the televised resources and web portal did not adequately prepare them for examinations. Like other contexts, students did not feel that they were prepared for a rapid shift to online learning.

Emergency and difficult policy contexts are not new to all teachers. Middle school teachers from three countries that have faced years of conflict prior to Covid-19 provide insight into how the teachers and communities in Libya, Palestine and Afghanistan adapted to support students to keep them learning when schools closed (Khlaif et al., 2020). This article highlights how some teachers, no matter what the context, find creative solutions to try to engage students in learning to minimise disruption to their education.

The seventh article reports the results of how teachers from Italy included students with special needs in learning during the Covid-19 lockdown (Parmigiani et al., 2020). The authors conclude that effective e-inclusion is influenced by the technology available, relationships with family, and being able to create personalised synchronous and asynchronous interactive learning activities. The children in this context are dependent on their parents, which amplifies digital inequities. For inclusion of teachers at vocational schools in Germany, it was found that school leadership needs to create and communicate a meaningful agenda or plan, there needs to be reliable technological infrastructure and teachers require the competencies to identify and implement digital teaching methods and tools (Delcker \& Ifenthaler, 2020).

Teacher preparedness was an emerging issue across most contexts. A global survey of secondary teachers examined how ready teachers and institutions were for emergency online teaching (Howard et al., 2020). The researchers identify four profiles: high, medium, low and mixed perceptions of readiness to teach online. The professional and institutional support needed for each profile group is identified. In Irish secondary schools, teachers were found to have a positive disposition towards technology and believed that, prior to Covid-19 closures, approaches to digital learning in their schools were aligned with best practice recommendations (Scully et al., 2021). However, as schools closed, differences emerged between rural and urban school leaders' responses and those in economically disadvantaged contexts. The pandemic appears to have amplified aspects of education systems that helped or hindered learning. The leaders in the study identified how the experience has influenced intended changes to their digital learning policies and the speed with which this might happen. 
The final article also draws on the experience of school leaders, in Catalonia (Palau et al., 2021). This article identified important aspects of education when school learning moves into the home. This includes the need for emotional support for students, communication with families and the increased workload teachers faced. The leaders identified a lack of planning for emergency situations and suggest how school practices should change following the pandemic.

\section{Equity, planning for the future and valuing teachers}

Three broad themes are evident across the articles in this special issue: technology and digital equity; the development of emergency response plans; and valuing teachers.

The technology used for learning at home varied from low to high tech. In low-tech homes, students watched national education television broadcasts or used texts or worksheets to continue with their learning. High-tech homes had fast broadband and access to interactive learning activities through computers, and mid-tech homes had slow or unreliable Internet, shared devices or only mobile phones to access materials and interact with their teacher and other students. Digital inequities were identified in most of the articles in this special issue and were correlated with rural-urban divides (for example, Bokayev et al., 2021; Scully et al., 2021), socio-economic context of households (for example, Greenhow et al., 2020; Scully et al., 2021) and the cultural context such as restrictions on girls' access to the Internet (Khlaif et al., 2020). The level of technology available and the educational context influenced the pedagogical practices as students learnt through prerecorded instructional videos, interactive online lessons, educational television and printed resources. Students in low-tech and low socio-economic households engaged less with learning (Scully et al., 2021). High-tech, high socio-economic households were likely to also be advantaged by correlating to parents with higher levels of education who could better support their children's learning (for example, Bokayev et al., 2021; Greenhow et al., 2020). This was particularly relevant for parents of younger children and children with special needs who played a significant role in their children's education during the pandemic (Palau et al., 2021; Parmigiani et al., 2020). Digital inequities can amplify educational inequities when formal education moves from the school to the home in times of crises.

A common recommendation across articles is the need to develop emergency response plans to prepare education systems for the future (Delcker \& Ifenthaler, 2020; Bokayev et al., 2021; Ewing \& Cooper, 2021; Palau et al., 2021). Although many resources have been invested in the last two decades to incorporate technology into education, the emergency situation derived from the pandemic has shown that education systems globally were not prepared to take on the challenge of implementing online or blended learning in schools (Reimers \& Schleicher, 2020). The types of preparation identified across the articles to prepare for emergency online teaching include developing better infrastructure to enable high-tech access for all students, communication plans, developing and supporting teacher competence in effective online distance pedagogical practices, and developing age-appropriate student competence in autonomous and collaborative learning with digital tools. Public policies in education should be oriented towards the teachers' professional learning within the transformation of educational models rather than the provision of technological resources. In addition, in emergency situations, teachers need to be able to provide emotional support for students (Palau et al., 2021; Yates et al., 2020), and for teachers of younger children and those with special needs they need to be confident in adapting their practices to collaborate with parents (Parmigiani et al., 2020). In addition, the blurring of the home and school boundaries has implications for future digital infrastructure policies. Educational leaders in the past have focused on the school as a setting for digital technology, and a revisioning to consider purpose rather than setting is needed (Scully et al., 2021).

There is a clear emphasis on how teachers have responded to the pandemic to support their students and continue to educate. There are innovative examples from both developing countries and highly digitised contexts of how teachers rapidly adapted to teaching and supporting students 
beyond the classroom environment through digital technology. This provides evidence for why the teaching profession globally should be celebrated. Unfortunately, in the current neoliberal global context, teachers are often situated as a 'problem'; rather than being celebrated, they are blamed for shortcomings (De Saxe et al., 2020). This is reflected within these articles in two ways: the first is a focus on assessment and accountability during the pandemic as identified in the US media (Greenhow et al., 2020), and the second is the critique of teachers' digital competence or online pedagogical practices. This selection of articles reflects that teachers work within national, local and schooling contexts which enhanced or limited their ability to respond in times of school closures and provides constructive insight to inform future support for teachers (for example, Howard et al., 2020). It is evident that teachers are essential members of their community in times of crises.

\section{Disclosure statement}

No potential conflict of interest was reported by the authors.

\section{Notes on contributors}

Louise Starkey is an Associate Professor at Victoria University of Wellington, New Zealand. Her research explores complexity theory, educational policy and practice associated with teaching and learning in the digital age. This includes considering the implications of digital infusion across the different aspects of schooling systems.

Miri Shonfeld's research deals with online learning environments, collaborative work, intercultural links and faculty development. She is currently the head of the Technology, Education, and Cultural Diversity (TEC) Center at Mofet Institute and a faculty member of the graduate programme in Technology in Education at Kibbutzim College of Education in Tel Aviv.

Sarah Prestridge is a senior researcher within the Griffith Institute of Educational Research, Griffith University, Australia. She investigates the nexus between digital pedagogies, teacher beliefs and professional development. In drawing these three areas together, her research has theorised how to change teachers' pedagogical practices; conceptualised professional online learning networks; and explored flexible distance education.

Mercè Gisbert Cervera is a professor in the Department of Pedagogy at Rovira i Virgili University, Tarragona, Spain, and the director of the interdisciplinary research group ARGET [Applied Research in Education and Technology]. Her research develops understanding of teacher digital competence and the use of digital tools in education.

\section{ORCID}

Louise Starkey (iD) http://orcid.org/0000-0002-8607-366X

\section{References}

Bokayev, B., Torebekova, Z., Davletbayeva, Z., \& Zhakypova, F. (2021). Distance learning in Kazakhstan: Estimating parents' satisfaction of educational quality during the Covid-19 pandemic. Technology, Pedagogy and Education, 30 (1), 25-37. https://doi.org/10.1080/1475939X.2020.1865192

De Saxe, J. G., Bucknovitz, S., \& Mahoney-Mosedale, F. (2020). The deprofessionalization of educators: An intersectional analysis of neoliberalism and education reform. Education and Urban Society, 52(1), 51-69. https://doi.org/10.1177/ 0013124518786398

Delcker, J., \& Ifenthaler, D. (2020). Teachers' perspective on school development at German vocational schools during the Covid-19 pandemic. Technology, Pedagogy and Education, 30(1), 121-135. https://doi.org/10.1080/1475939X. 2020.1857826

Ewing, L.-A., \& Cooper, H. (2021). Technology-enabled remote learning during Covid-19: Perspectives of Australian teachers, students and parents. Technology, Pedagogy and Education, 30(1), 39-54. https://doi.org/10.1080/1475939X. 2020.1868562

Fiş Erümit, S. (2020). The distance education process in K-12 schools during the pandemic period: Evaluation of implementations in Turkey from the students' perspective. Technology, Pedagogy and Education, 30(1), 71-90. https://doi.org/10.1080/1475939X.2020.1856178 
Greenhow, C., Lewin, C., \& Staudt Willet, K. B. (2020). The educational response to Covid-19 across two countries: A critical examination of initial digital pedagogy adoption. Technology, Pedagogy and Education, 30(1), 5-23. https:// doi.org/10.1080/1475939X.2020.1866654

Howard, S. K., Tondeur, J., Siddiq, F., \& Scherer, R. (2020). Ready, set, go! Profiling teachers' readiness for online teaching in secondary education. Technology, Pedagogy and Education, 30(1), 137-154. https://doi.org/10.1080/1475939X. 2020.1839543

Khlaif, Z. N., Salha, S., Affouneh, S., Rashed, H., \& ElKimishy, L. A. (2020). The Covid-19 epidemic: Teachers' responses to school closure in developing countries. Technology, Pedagogy and Education, 30(1), 91-105. https://doi.org/10.1080/ 1475939X.2020.1851752

Palau, R., Fuentes, M., Mogas, J., \& Cebrián, G. (2021). Analysis of the implementation of teaching and learning processes in Catalan schools during the Covid-19 lockdown. Technology, Pedagogy and Education, 30(1), 179-195. https://doi. org/10.1080/1475939X.2020.1863855

Parmigiani, D., Benigno, V., Giusto, M., Silvaggio, C., \& Sperandio, S. (2020). E-inclusion: Online special education in Italy during the Covid-19 pandemic. Technology, Pedagogy and Education, 30(1), 107-120. https://doi.org/10.1080/ 1475939X.2020.1856714

Reimers, F., \& Schleicher, A. (2020). A framework to guide an education response to the COVID-19 pandemic of 2020. OECD. http://www.oecd.org/education/

Scully, D., Lehane, P., \& Scully, C. (2021). 'It is no longer scary': Digital learning before and during the Covid-19 pandemic in Irish secondary schools. Technology, Pedagogy and Education, 30(1), 155-177. https://doi.org/10.1080/1475939X. 2020.1854844

Yates, A., Starkey, L., Egerton, B., \& Flueggen, F. (2020). High school students' experience of online learning during Covid19: The influence of technology and pedagogy. Technology, Pedagogy and Education, 30(1), 55-69. https://doi.org/10. 1080/1475939X.2020.1854337 